\title{
EVALUASI IMPLEMENTASI KEBIJAKAN PENANGGULANGAN BENCANA HIDROMETEREOLOGI BIDANG KESEHATAN DI KABUPATEN ACEH UTARA
}

\author{
Mulyadi $^{1}$, Eka Sutrisna ${ }^{2}$ \\ Program Studi SI Keperawatan, STIKes Getsempena Lhoksukon \\ Mulyadim91@gmail.com ${ }^{1}$, ekasutrisna84@gmail.com²
}

\begin{abstract}
Aceh Utara District has 16 Districts that are prone to flood disasters so that preparedness is more focused on flood disaster management while remaining vigilant of other natural and non-natural disasters. the health sector is one of the sectors that has been prepared for disaster, This can be seen from the health team that has been formed and involved in disaster management that often occurs in North Aceh District. This study aims to analyze the support for disaster management preparedness policies in the health sector in Aceh Utara District and determine the level of compliance of stakeholders in carrying out their main duties and institutional functions. This type of research uses a qualitative approach. Informants will be selected based on the principles of qualitative research including key informants (BPBD and the North Aceh District Health Office) and supporting informants (Puskesmas, Indonesian Red Cross and the general public. The research stages were conducting policy evaluation, compliance and stakeholder coordination. Research variables are human resources, infrastructure and implementation of disaster management policies in the health sector. The data collection tool is an interview guide. Data analysis used data reduction, data presentation and drawing conclusions.The results showed that the human resources available in North Aceh Regency were classified as ready in quantity in providing health services before, during or after a disaster, but for the health office it was still short on staff with the qualifications to be able to make disaster-prone maps and contingency plans. Facilities and infrastructure in the form of equipment owned by the health office are adequate in providing health services. However, the health office still relies heavily on BPBD in providing supporting tools such as rubber boats, transportation that can help directly to the area during a disaster. The health office is not obedient in implementing disaster management policies during pre-disaster and post-disaster periods.
\end{abstract}

Keywords: Countermeasures, Evaluation, Implementation; Policy; Hydrometeorological Disaster.

\begin{abstract}
ABSTRAK
Kabupaten Aceh Utara memiliki 16 Kecamatan rawan bencana banjir untuk itu kesiapsiagaan lebih difokuskan pada penanggulangan bencana banjir dengan tetap mewaspadai terjadinya bencana alam dan non alam lainnya, sektor kesehatan merupakan salah satu sektor yang dipersiapkan dalam menghadapi bencana, terlihat dari tim kesehatan yang sudah terbentuk dan terlibat dalam penanggulangan bencana yang sering terjadi di Kabupaten Aceh Utara. Penelitian ini bertujuan untuk menganalisis dukungan kebijakan kesiapsiagaan penanggulangan bencana bidang kesehatan di Kabupaten Aceh Utara dan mengetahui tingkat kepatuhan stakeholder dalam menjalankan tugas pokok dan fungsi institusinya.

Jenis dari penelitian ini menggunakan pendekatan kualitatif. Informan-informan akan dipilih berdasarkan prinsip-prinsip penelitian kualitatif meliputi informan kunci (BPBD dan Dinas Kesehatan Kabupaten Aceh Utara) dan informan pendukung (Puskesmas, Palang Merah Indonesia dan masyarakat umum). Tahapan riset yaitu melakukan evaluasi kebijakan, kepatuhan, dan koordinasi stakeholder. Variabel penelitian adalah sumber daya manusia, sarana prasarana dan implementasi kebijakan penanggulangan bencana di bidang kesehatan. Alat pengumpul data berupa panduan wawancara. Analisis data yang digunakan reduksi data, penyajian data dan penarikan kesimpulan.

Hasil penelitian diperoleh sumber daya manusia yang tersedia di Kabupaten Aceh Utara tergolong siap secara kuantitas dalam memberikan pelayanan kesehatan sebelum, saat atau setelah bencana, tetapi untuk dinas kesehatan masih kekurangan tenaga dengan kualifikasi mampu membuat peta rawan bencana dan rencana kontingensi. Sarana dan prasarana berupa peralatan yang dimiliki oleh dinas kesehatan sudah memadai dalam memberikan pelayanan kesehatan. Akan tetapi Dinas kesehatan masih sangat bergantung kepada BPBD dalam penyediaan alat pendukung seperti perahu
\end{abstract}


karet, transpotasi yang dapat membantu langsung ke daerah saat bencana. Dinas kesehatan kurang patuh dalam mengimplementasikan kebijakan penanggulangan bencana pada saat pra bencana dan pasca bencana.

Kata Kunci: Evaluasi, Implementasi, Kebijakan,Penanggulanagan Bencana Hidrometereologi

\section{PENDAHULUAN}

Kabupaten Aceh Utara adalah salah satu wilayah rawan bencana dalam Provinsi Aceh. Kabupaten ini merupakan kawasan rawan bencana alam banjir yang terjadi pada setiap tahun pada skala rendah, menengah dan tinggi disebabkan oleh curah hujan diatas normal sehingga sistim pengaliran air alamiah yang terdiri dari sungai dan anak sungai dan saluran drainase tidak mampu menampung akumulasi air hujan.

Kabupaten Aceh Utara memiliki 16 Kecamatan rawan Bencana Banjir untuk itu kesiapsiagaan lebih difokuskan pada Penanggulangan Bencana banjir dengan tetap mewaspadai terjadinya Bencana Alam dan Non Alam lainnya. Dalam rangka meningkatkan kewaspadaan di Kabupaten Aceh Utara telah dibentuk unit BPBD Rescue dengan jumlah anggota 24 orang sebagai ujung tombak Penanggulangan Bencana yang dibagi dalam berberapa regu dan setiap regu bertugas sebagai piket jaga 24 jam untuk merespon laporan masyarakat. Dari keseluruhan kecamatan, 16 kecamatan diantaranya adalah wilayah rawan bencana alam banjir yang terjadi setiap tahun yang berdampak kepada masyarakat di 111 gampong (BNPB, 2011).

Pelaksanaan tugas Penanggulangan Bencana secara efektif dan efisien serta sinergis dengan instasi lembaga terkait pihak Pemerintah Kabupaten Aceh Utara telah membentuk Badan Penanggulangan Bencana Daerah Kabupaten Aceh Utara dengan Qanun No 3 tahun 2010. Salah satu sektor yang membutuhkan kesiapsiagaan adalah sektor kesehatan. Kesehatan merupakan salah satu sektor yang mendapat perhatian besar bagi tim penanggulangan bencana.
Bencana yang panjang akan berdampak sangat buruk bagi kesehatan, karena sebab tersebut kesiapsiagaan dalam sektor dibidang kesehatan adalah hal yang perlu diperhatikan secara khusus. Penanganan bencana di lapangan sangat bergantung pada stakeholdernya, misalnya BPBD dan khusus di bidang kesehatan ada kordinator tanggap darurat kesehatan yang dikordinir oleh dinas kesehatan, serta ada rumah sakit. Ketiga pihak ini mempunyai peran yang berbeda-beda di lapangan.

Sektor dibidang kesehatan adalah salah satu sektor yang telah disiapkan dalam menghadapi bencana, hal tersebut dapat dilihat dari tim kesehatan yang telah terlibat dan terbentuk dalam penanggulangan bencana yang sering terjadi di Kabupaten Aceh Utara. Hal ini terlihat dari laporan BPBD yang menunjukkan peran serta petugas kesehatan dalam menanggulangi bencana (Peraturan Kepala Badan Nasional Penanggulangan Bencana (BNPB) No. 3 Tahun 2013). Tim kesehatan sebagai bagian dari tim penanggulangan bencana sebagai penyelenggara dalam penanggulangan bencana di daerah yang meliputi tahap pra bencana, tanggap darurat, dan pasca bencana sesuai kesiapsiagaan yang baik, khususnya kesiapsiagaan petugas yang terlibat langsung dalam penanggulangan bencana termasuk bidang kesehatan. Berdasarkan survey awal yang dilakukan diketahui bahwa tim kesehatan sudah terlibat aktif dalam penanggulangan masalah kesehatan akibat bencana, khususnya bencana banjir yang kerap menimpa kabupaten Aceh Utara.

Berdasarkan penelusuran dokumen laporan penilaian kebutuhan kesehatan tim penanggulangan diketahui bahwa tim 
kesehatan sering mengalami kekurangan peralatan bantuan medis, transportasi dan obat-obatan. Kondisi ini sering terjadi pada setiap bencana banjir, hal ini mengakibatkan pelayanan kesehatan di pengungsian jadi terhambat karena pemenuhan kebutuhan obat tidak tersedia secepat mungkin. Selain itu berdasarkan wawancara dengan dinas kesehatan bahwa dana yang tersedia untuk mengatasi bencana juga menjadi faktor yang menghambat penyediaan material pendukung pelayanan kesehatan, sehingga tak jarang dinas kesehatan memanfaatkan dahulu material fisik dan obat-obatan yang lazimnya digunakan untuk kebutuhan sehari-sehari di Puskesmas, dan sering jumlahnya juga terbatas.

Tujuan penelitian adalah menganalisis dukungan kebijakan kesiapsiagaan penanggulangan bencana bidang kesehatan di Kabupaten Aceh Utara dan mengetahui tingkat kepatuhan stakeholder dalam menjalankan tugas pokok dan fungsi institusinya dan mengetahui model koordinasi stakeholder dalam penanggulangan bencana bidang kesehatan.

\section{METODE}

Penelitian ini menggunakan pendekatan kualitatif. Variabel penelitian adalah dukungan kebijakan kesiapsiagaan, tingkat kepatuhan stakeholder dan model koordinasi stakeholder dalam penanggulangan bencana hidrometeorologi bidang kesehatan. Peneliti melakukan penelitian di Kabupaten Aceh Utara. Pemilihan Kabupaten ini sebagai tempat. Waktu penelitian dilakukan dari tanggal 12 Maret sampai tanggal 10 September tahun 2020. Informan-informan akan dipilih berdasarkan prinsip-prinsip pada penelitian kualitatif yaitu kesesuaian (Appropiateress) dan kecukupan (Adequancy) meliputi informan kunci (BPBD dan Dinas Kesehatan Kabupaten Aceh Utara) dan informan pendukung
(Puskesmas, Palang Merah Indonesia dan masyarakat umum). Penelitian ini mengambil sampel secara purposive dimana peneliti ingin melihat bagaimana implementasi kebijakan penanggulangan bencana bidang kesehatan di Kabupaten Aceh Utara.

Menurut Sugiyono (2010), analisa data merupakan teknik yang sangat penting dalam suatu penelitian data yang dianalisis secara kualitatif, serta kutipan dari hasil wawancara ditampilkan untuk mendukung analisis. Analisa data yang digunakan dalam memecahkan masalah yang timbul dari penelitian sejak awal sampai selesainya pengumpulan data. Proses penelitian dengan menggunakan model analisis interaktif melalui tiga tahapan pengumpulan data, adalah :

1. Reduksi Data.

2. Penyajian Data.

3. Penarikan Kesimpulan atau Verifikasi.

HASIL

Dukungan dalam Implementasi Penanggulangan Bencana

Sumber Daya Manusia

Sumber daya manusia adalah seluruh tenaga kesehatan yang dialokasikan untuk mendukung implementasi kebijakan penanggulangan bencana bidang kesehatan di Kabupaten Aceh Utara. Berdasarkan profil BPBD Kabupaten Aceh Utara diketahui jumlah personil yang terlibat dalam penanganan bencana khususnya di bidang kesehatan, secara rinci terlihat dalam tabel berikut ini:

Tabel 1. Jumlah Personil Penanggulangan

Bencana Bidang Kesehatan di Kabupaten Aceh Utara Tahun 2020

\begin{tabular}{|c|c|c|c|}
\hline No & Instansi & $\begin{array}{c}\text { Jumlah } \\
\text { Personil } \\
\end{array}$ & $\begin{array}{c}\text { Keteran } \\
\text { gan }\end{array}$ \\
\hline 1 & $\begin{array}{l}\text { BPBD } \\
\text { Kabupaten Aceh } \\
\text { Utara }\end{array}$ & 20 orang & $\begin{array}{l}\text { Pernah } \\
\text { mengikuti } \\
\text { pelatihan }\end{array}$ \\
\hline 2 & $\begin{array}{l}\text { Dinas Kesehatan } \\
\text { Kabupaten Aceh } \\
\text { Utara }\end{array}$ & 20 orang & $\begin{array}{l}\text { Pernah } \\
\text { mengikuti } \\
\text { pelatihan }\end{array}$ \\
\hline 3 & Siaga & 30 orang & Pernah \\
\hline
\end{tabular}




\begin{tabular}{lll} 
Bencana & & $\begin{array}{l}\text { mengikuti } \\
\text { pelatihan }\end{array}$ \\
$4 \quad \begin{array}{l}\text { Palang Merah } \\
\text { Indonesia }\end{array}$ & 112 orang & $\begin{array}{l}20 \quad \text { orang } \\
\text { terlatih, } 92 \\
\text { orang } \\
\text { relawan }\end{array}$ \\
\hline Jumlah & 182 orang & \\
\hline
\end{tabular}

Sumber : Profil BPBD Kabupaten Aceh Utara

Tabel 1 di atas menunjukkan bahwa kuantitas sumber daya manusia di bidang kesehatan tergolong mencukupi, dan hampir keseluruhannya merupakan tenaga yang sudah dilatih. Hal ini sesuai dengan pernyataan kepala dinas kesehatan Kabupaten Aceh Utara yang mengatakan,

"Kalau ditanya SDM di dinas kesehatan saya piker cukup untuk memberikan pelayanan kesehatan selama bencana, belum lagi dibantu sama tenaga PMI yang cukup banyak, saya yakin sdm di sini cukup tersedia".

Berdasarkan hasil di atas, maka dapat diketahui bahwa pelayanan kesehatan pada bencana tidak bisa sembarangan orang, sebab secara kualitas haruslah tenaga kesehatan yang memiliki pengalamanan pelatihan. Hasil di atas menunjukkan bahwa sumber daya manusia yang tersedia di Kabupaten Aceh Utara tergolong siap secara kuantitas dan kualitas dalam memberikan pelayanan kesehatan sebelum, saat atau setelah bencana. Maka dapat dipastikan bahwa dukungan sumber daya manusia cukup baik dalam implementasi kebijakan penanggulangan bencana di Kabupaten Aceh Utara.

\section{Sarana dan Prasarana}

Sarana dan Prasarana adalah seluruh potensi fisik yang dialokasikan untuk mendukung implementasi kebijakan penanggulangan bencana bidang kesehatan di Kabupaten Aceh Utara. Berdasarkan profil BPBD Kabupaten Aceh Utara diketahui sarana dan prasarana berupa peralatn yang digunakan dalam penanganan bencana khususnya di bidang kesehatan dan dimiliki oleh stakeholder, secara rinci terlihat dalam tabel berikut ini:

Tabel 2. Peralatan yang dimiliki Stakeholder dalam Penanggulangan Bencana Bidang Kesehatan di Kabupaten Aceh Utara Tahun 2020

\begin{tabular}{|c|c|c|c|}
\hline NO & $\begin{array}{c}\text { NAMA } \\
\text { PERALATAN }\end{array}$ & $\begin{array}{l}\text { MEREK } \\
\text { /TYPE }\end{array}$ & $\begin{array}{c}\text { JUML } \\
\text { AH }\end{array}$ \\
\hline I & \multicolumn{3}{|c|}{ Alat Angkut/Mobilisasi Laut/Sungai } \\
\hline 1 & $\begin{array}{l}\text { Perahu Fiber } 10 \\
\text { Penumpang }\end{array}$ & $\begin{array}{l}\text { Boat } \\
\text { Yard } \\
\text { Zebec/Ba }\end{array}$ & 6 Unit \\
\hline 2 & $\begin{array}{l}\text { Perahu Karet } \\
\text { (Rubber Boat) }\end{array}$ & $\begin{array}{l}\text { se } \\
\text { Marine } \\
\text { Yamaha }\end{array}$ & $\begin{array}{l}4 \text { Unit } \\
11\end{array}$ \\
\hline 3 & Mesin Boat & Enduro & Unit \\
\hline II & $\begin{array}{l}\text { Alat } \\
\text { Darat }\end{array}$ & ilisasi/Tran & sportasi \\
\hline 1 & $\begin{array}{l}\text { Minibus } 4 \text { (empat) } \\
\text { Roda }\end{array}$ & $\begin{array}{l}\text { Toyota } \\
\text { Innova } \\
\text { Toyota }\end{array}$ & 1 Unit \\
\hline 2 & Pick Up & Kijang & 1 Unit \\
\hline III & Alat Perlindungan/S & nelter/Tend & \\
\hline 1 & Tenda Posko & $\begin{array}{l}\text { Bahan } \\
\text { Uno } 450 \\
\text { Bahan } \\
\text { Besi/Can }\end{array}$ & 1 Unit \\
\hline 2 & Tenda Tratak & $\begin{array}{l}\text { vas } \\
\text { Bahan }\end{array}$ & 4 Unit \\
\hline 3 & Tenda Keluarga & $\begin{array}{l}\text { Canvas } \\
\text { Bahan }\end{array}$ & 5 Unit \\
\hline 4 & Tenda Komando & $\begin{array}{l}\text { Canvas } \\
\text { Bahan }\end{array}$ & 1 Unit \\
\hline 5 & Tenda Pleton & $\begin{array}{l}\text { Canvas } \\
\text { Bahan }\end{array}$ & 1 Unit \\
\hline 6 & Tenda Peralatan & Canvas & $\begin{array}{l}1 \text { Unit } \\
25\end{array}$ \\
\hline 7 & Velbet & & $\begin{array}{c}\text { Unit } \\
10\end{array}$ \\
\hline 8 & $\begin{array}{l}\text { Tandu } \\
\text { Tandu Air (Bucket }\end{array}$ & & Unit \\
\hline 9 & Straecer) & & 1 Unit \\
\hline 10 & $\begin{array}{l}\text { Brethling Aparatus } \\
\text { Safety Cone (Marka }\end{array}$ & & $\begin{array}{c}2 \text { Set } \\
18\end{array}$ \\
\hline 11 & Kerucut) & & $\begin{array}{l}\text { Unit } \\
12\end{array}$ \\
\hline 12 & Traffic Botton & & $\begin{array}{l}\text { Unit } \\
1 \\
\text { Gulun }\end{array}$ \\
\hline 13 & Tali Rafling & & $\mathrm{g}$ \\
\hline 14 & Masker Gas & & 3 Buah \\
\hline
\end{tabular}


ISSN 2623-1573 (Print)

\begin{tabular}{|c|c|c|c|}
\hline 15 & Masker Biasa & & $\begin{array}{c}20 \\
\text { Buah }\end{array}$ \\
\hline 16 & Senter Kepala & Bahan & $\begin{array}{l}5 \text { Buah } \\
40\end{array}$ \\
\hline 17 & Kantong Mayat & $\begin{array}{l}\text { Canvas } \\
\text { King's/K }\end{array}$ & Buah \\
\hline 18 & Sepatu Safety & risbow & $\begin{array}{c}65 \text { Psg } \\
50\end{array}$ \\
\hline 19 & Rompi & & $\begin{array}{c}\text { Buah } \\
28\end{array}$ \\
\hline 20 & Life Jacket & & Buah \\
\hline 21 & Ring Bouy & & $\begin{array}{c}3 \text { Buah } \\
37\end{array}$ \\
\hline 22 & Jas Hujan & & $\begin{array}{c}\text { Buah } \\
35\end{array}$ \\
\hline 23 & Helm Safety & & Buah \\
\hline 24 & $\begin{array}{ll}\text { Sepatu Boat } & \text { Karet } \\
\text { Sarung } & \text { Tangan }\end{array}$ & & 45 Psg \\
\hline 25 & Panjang & Karet & $\begin{array}{c}2 \text { Psg } \\
25\end{array}$ \\
\hline 26 & Sangkur & Stainless & Buah \\
\hline 27 & $\begin{array}{l}\text { Senter Charger } \\
\text { Senter Water } \\
\text { Resistance }\end{array}$ & Krisbow & 2 Unit \\
\hline IV & Alat Komunikasi dan & Elektronik & \\
\hline 1 & Radio SSB & $\begin{array}{l}\text { Kenwoo } \\
\text { d } \quad \text { TM- }\end{array}$ & 1 Unit \\
\hline 2 & $\begin{array}{l}\text { Radio RIG ( VHF) } \\
\text { Radio RIG Dual } \\
\text { Band }\end{array}$ & $\begin{array}{l}271 \\
\text { Icom/Ke } \\
\text { nwood }\end{array}$ & 1 Unit \\
\hline 4 & HT Dual Band & Yaesu & 9 Unit \\
\hline 5 & Tower dan Repiter & & 1 Unit \\
\hline 6 & Facimile & $\mathrm{c}$ & 3 Unit \\
\hline 7 & $\begin{array}{l}\text { GPS Garmin } \\
\text { Teropong Binocular }\end{array}$ & & 2 Unit \\
\hline 8 & Infra Red & & 1 Unit \\
\hline 9 & Handy cam & Sony & 1 Unit \\
\hline 10 & Camera Digital & Canon & 3 Unit \\
\hline 11 & Proyektor Infocus & Sony & 1 Unit \\
\hline 12 & Mega Phone & TOA & 3 Unit \\
\hline 13 & $\begin{array}{l}\text { Wire Less } \\
\text { Lampu Sorot } 500\end{array}$ & TOA & 1 Unit \\
\hline 14 & Watt & Krisbow & 2 Unit \\
\hline 15 & Kabel Roll & Krisbow & 3 Roll \\
\hline $\mathrm{V}$ & Alat/Peralatan Selam & & \\
\hline 1 & Witesuit & ScubaPro & 2 Set \\
\hline 2 & BCD & ScubaPro & 2 Set \\
\hline 3 & Weigth Belt & ScubaPro & $2 \mathrm{Set}$ \\
\hline 4 & Regulator & ScubaPro & 2 Set \\
\hline 5 & Octopus & ScubaPro & 2 Set \\
\hline 6 & Booties & ScubaPro & 2 Set \\
\hline
\end{tabular}

\begin{tabular}{|c|c|c|c|}
\hline & Twin Jet Fins & ScubaPro & 2 Set \\
\hline & Hand Gloves Full & & \\
\hline 8 & Leather under water & ScubaPro & 2 Set \\
\hline 9 & $\begin{array}{l}\text { Head Lamp under } \\
\text { water }\end{array}$ & AmScud & 2 Set \\
\hline 10 & $\begin{array}{l}\text { Air Tank Scuba Pro } \\
\text { Under Water Knife }\end{array}$ & AmScud & 2 Set \\
\hline 11 & $\begin{array}{l}\text { Titanium } \\
\text { Spare }\end{array}$ & AmScud & 2 Set \\
\hline 12 & Metaltech & ScubaPro & 1 Set \\
\hline & Fullfoot & ScubaPro & 2 Set \\
\hline VI & Alat Pendukung & & \\
\hline 1 & Mesin Genset & $\begin{array}{l}\text { Firman/ } \\
\text { Krisbow }\end{array}$ & 2 Unit \\
\hline 2 & $\begin{array}{l}\text { Chainsaw Kayu } \\
\text { Mesin Potong }\end{array}$ & Stihl & 2 Unit \\
\hline 3 & $\begin{array}{l}\text { Rumput } \\
\text { Tangki Air Portable }\end{array}$ & $\begin{array}{l}\text { Tanaka } \\
\text { Poly }\end{array}$ & 2 Unit \\
\hline 4 & 1 Ton & $\begin{array}{l}\text { Tank } \\
\text { Honda }\end{array}$ & 8 Unit \\
\hline 5 & Mesin Kompresor & GX & 1 Unit \\
\hline 6 & $\begin{array}{l}\text { Mesin Pompa air } \\
\text { Tangga Ladder }\end{array}$ & Robin & 1 Unit \\
\hline 7 & Heavy Duty & Alloy & 1 Unit \\
\hline
\end{tabular}

Berdasarkan tabel di atas dapat diketahui bahwa peralatan yang dimiliki tim penanggulangan bencana tergolong lengkap dan cukup dalam memenuhi pelayanan kesehatan. Hal tersebut sama dengan pernyataan informan dalam wawancara mendalam dengan kepala seksi bidang logistic BPBD kabupaten Kota berikut ini, "Selama ini, alat kita selalu cukup dalam menangani bencana yang terjadi, alat-alat yang mendasar dalam member pertolongan darurat kita sudah siapkan, jadi kalau alat kita didukung penuh".

Hal ini juga dijelaskan oleh anggota PMI berikut ini, " Alat-alat yang dibutuhkan dalam penanggulangan bencana, PMI ada, tapi tidak selengkap punya BPBD, $B P D B$ itu alatnya lengkap semua dalam memberikan pelayanan penanggulangan bencana”.

Hasil wawancara menunjukkan bahwa ketersediaan peralatan sarana dan prasarana dalam memberikan pelayanan kesehatan sudah cukup tapi khusus untuk BPBD, akan tetapi untuk dinas kesehatan yang secara khusus bertanggung jawab 
dalam memberikan pelayanan kesehatan tergolong kurang peralatan pendukungnya, seperti pernyataan informan kordinator pelayanan penanggulangan bencana berikut ini, "Untuk memberikan pelayanan kesehatan kita tinggal keluarkan dari APBD yang ada, kalau kurang kita biasanya minta bantuan Provinsi. Untuk pelayanan kesehatan kita punya alat yag cukup, biasanya Puskesmas juga kita suruh bawa saat bencana. Tapi untuk wilayah yang sangat besar dampak bencananya seperti banjir, kita tidak bisa langsung menuju kesana, karena kita kekurangan perahu karet, selain itu tenda untuk menampung masyarakat yang berobat juga tidak ada, jadi kita selalu berkordinasi dengan BPBD untuk penyediaan tempatnya."

Hal yang hampir sama juga dinyatakan oleh petugas Puskesmas Nibong berikut ini, “ Alat-alat yang kita gunakan dari Puskesmas, karena itu memang intruksi dari dinas kabupaten, biasanya kalau obat kita tinggal terima aja daftarnya dari dinas kesehatan meskipun itu tergantung permintaan kita"

Berdasarkan hasil wawancara di atas dapat diketahui bahwa sarana dan prasarana berupa peralatan yang dimiliki oleh dinas kesehatan sangat kurang. Dinas kesehatan sangat bergantung kepada BPBD dalam penyediaan alat pendukung, jadi meskipun sarana dan peralatan pelayanan kesehatan di dinas kesehatan ada dalam memberikan pelayanan kesehatan, tapi pelayanan kesehatan dapat terganggu karena tidak tersedianya sarana pendukung tersebut, misalnya tenda ataupun kapal karet.

\section{Implementasi Kebijakan Penang- gulangan Bencana}

\section{Pra Bencana}

Kepatuhan dalam implementasi penanggulangan bencana berdasarkan pada kebijakan kementerian kesehatan dalam penanggulangan bencana yaitu Kepmenkes RI Nomor 145 Tahun 2007 tentang Pedoman Penanggulangan Bencana di Bidang Kesehatan

Berdasarkan wawancara mendalam diketahui kepatuhan dalam implementasi kebijakan penanggulangan bencana seperti yang dinyatakan oleh Kepala Dinas Kesehatan berikut, "Kami biasanya mengumpulkan tim kesehatan yang sudah di SK kan, terus membuat rencana untuk membuat program persiapan untuk kesiapan bencana, setelah itu kami melakukan pelatihan atau mengirimkan tim untuk mengikuti pelatihan di luar,kemudian membentuk tim reaksi cepat, setelah itu kami mengkordinasikan hasilnya dengan BPBD untuk membantu mempersiapkan hal-hal yang tidak kami miliki"

Berdasarkan wawancara di atas diketahui bahwa implementasi kebijakan penanggulangan bencana bidang kesehatan belum secara keseluruhan dijalankan oleh Dinas Kesehatan Kabupaten Aceh Utara. Beberapa aktivitas yang tidak tampak dalam penanggulangan bencana antara lain, pembuatan peta deomedik rawan bencana dan perencanaan kontingensi. Berdasarkan wawancara mendalam kedua hal ini tidak dilakukan disebabkan karena tim dinas kesehatan tidak memiliki kemampuan membuat peta deomedik sehingga dinas kesehatan beharap pada BPBD kabupaten kota untuk membuat peta tersebut, hal ini sesuai dengan pernyataan kepala BPBD Kabupaten Aceh Utara berikut ini, " Dinas kesehatan kami undang untuk mengkordinasikan rencana pelayanan bidang kesehatan dalam penanggulangan bencana, sehingga melalui kordinasi tersebut BPBD dapat merencanakan secara utuh, beberapa hal yang diminta oleh dinas kesehatan adalah pembuatan peta deomedik oleh BPBD dengan asumsi agar terjadi keseragaman dalam memandang wilayah yang menjadi lokasi penanggulangan bencana"

Perencanaan kontingensi tidak dibuat oleh dinas kesehatan karena dinas 
kesehatan belum mampu memprediksi alternative perencanaan lain yang mungkin muncul sehingga pelayanan kontingensi menyesuaikan dengan kondisi di lapangan. Hal ini sesuai dengan pernyataan kordinator pelayanan penanggulangan bencana bidang kesehatan Dinas Kesehatan Kabupaten Aceh Utara. "Perencanaan kontingensi tidak kami buat karena kami susah memprediksi apa yang terjadi saat bencana, sehingga dinas kesehatan bergantung pada BPBD untuk mengembangkan rencana kontingensi dan dinas akan menyesuaikan"

Berdasarkan hal di atas beberapa dukungan yang menguatkan proses iimlementasi pada saat pra bencana adalah, kemampuan sumber daya manusia. Dinas kesehatan harus memiliki sumber daya manusia yang dapat melakukan dua kegiatan yang tidak bisa dilakukan dengan cara melakukan pelatihan. Selain sumber daya manusia komunikasi adalah hal yang paling kuat dalam mendukung implementasi kebijakan penanggulangan bencana pada saat pra bencana, hal ini ditandai dengan adanya kordinasi dan pertemuan antara dinas kesehatan dan BPBD kabupaten kota.

\section{Saat Bencana}

Implementasi kebijakan saat bencana adalah realisasi penanggulangan bencana bidang kesehatan sesuai dengan kebijakan yang telah ditetapkan dan dilaksanakan saat bencana.

Berikut ini pernyataan Kepala Dinas Kesehatan Kabupaten Aceh Utara mengenai implementasi kebijakan penanggulangan bencana bidag kesehatan pada saat bencana, "Kalau pra bencana dinas kesehatan tidak terlalu berperan aktif, tapi kalau saat bencana tim kesehatan sangat berperan aktif misalnya kami menyiapkan dan mengirim tenaga kesehatan dan obata-obatan, kemudian kami berkordinasi dengan rumah sakit untuk upaya tindakan lanjutan, kemudian satuan lapangan dari BPBD, agar di lapangan mudah maka petugas puskesmas kami kerahkan membantu secara teknis, dan kami juga melakukan beberapa penilaian terhadap status pengungsi, pemberian imunisasi dan penyiapan makanan bergizi agar tidak terjadi kelaparan, dan yang paling penting kami lakukan adalah melakukan surveilans tentang dampak bencana ini bagi kesehatan masyarakat khususnya untuk pengungsi"

Begitu juga dengan pernyataan kepala Puskesmas Nibong berikut ini, " Kalau udah banjir di sini, wah pasti kami akan sangat sibuk, selain jalanan program Puskesmas kami juga menjalankan program tambahan, kalau gak dari hati ana tekerjai, biasanya kami itu bantu menyusun menu di dapur uтum, melakukan survey lingkungan di pemukiman warga dan pengungsian, dan melakukan imunisasi campak pada bayi”.

Berdasarkan hasil di atas dapat disimpulkan bahwa dinas kesehatan sudah mampu dalam mengimplementasikan kebijakan penanggulangan bencana bidang kesehatan sesuai dengan kepmenkes yang ada. Keseluruhan aktivitas penanggulangan bencana pada saat bencana dapat dilakukan oleh dinas kesehatan.

\section{Pasca Bencana}

Implementasi kebijakan pasca bencana adalah realisasi penanggulangan bencana bidang kesehatan sesuai dengan kebijakan yang telah ditetapkan dan dilakukan pada saat bencana sudah berakhir.

Berikut adalah hasil wawancara dengan tim kesehatan dalam penanggulangan bencana bidang kesehatan pada saat pasca bencana, salah satunya adalah kordinator pelayanan penanggulangan bencana bidang kesehatan Dinas Kesehatan Kabupaten Aceh Utara, " Kegiatan yang kami lakukan kalau habis bencana ini hamppir sama dengan program yang basa kami 
lakukan di dinas atau puskesmas, yang harus dilakukan adalah gimana agar pengungsi-pengungsi itu tidak kena wabah, jadi kami harus periksa gizi mereka,anak mereka, lingkungannya, kalau gak bisa kami tangani kami bawa ke rumah sakit lewat rujukan. Jadi Puskesmas biasanya buat posko kesehatan di pengungsian”.

Berdasarkan hasil di atas maka dapat disimpulkan bahwa implementasi kebijakan pada penanggulangan bencana dibidang kesehatan pada saat pasca bencana sudah hampir sesuai dengan Kepmenkes yang ditetapkan. Meskipun aktivitas penilaian gizi tidak dilakukan, tetapi program penyusunan diet terlalu menambah keparahan kondisi gizi.

Hal di atas menunjukkan bahwa dinas kesehatan masih tergolong kurang patuh didalam pengimplementasikan kebijakan penangulangan bencana dibidang kesehatan, sebab masih ada aktivitas pasca bencana yang belum dilaksanakan. Bila dikaitkan dengan dukungan, maka dukungan sumber daya manusia secara kuantitas perlu diperhatikan di posko, dari pengalaman penulis pada saat bencana terlihat bahwa tenaga kesehatan yang ada di posko jumlanya sangat sedikit 1-3 orang dan dibagi berdasarkan shift setiap 8 jam di posko. Maka secara kuantitas sumber daya manuia mempengaruhi implementasi kebijakan penanggulangan bencana khususnya pada point penentuan gizi sebagai dasar intervensi kesehatannya.

\section{PEMBAHASAN}

\section{Analisis Dukungan Sumber Daya Manusia dalam Implementasi Kebijakan Penanggulangan Bencana Bidang Kesehatan.}

Keberhasilan proses pengimplementasian kebijakan bergantung pada kemampuan memanfaatkan sumberdaya yang telah tersedia. Manusia adalah sumberdaya yang sangat penting didalam penentuan keberhasilan pada proses implementasi. Hasil penelitian menunjukkan bahwa faktor sumber daya manusia mempunyai peran yang sangat penting dalam pengimplementasian kebijakan pada penanggulangan kebencanaan. Sumber daya manusia yang dimaksud meliputi kuantitas atau jumlah tenaga maupun kualitas tenaga kesehatan dalam melakukan penanggulangan bencana.

Menurut Edward dalamWidodo (2011) bahwa implementasi kebijakan akan gagal bila belum ada dukungan dari sumber daya manusia baik secara kualitas serta kuantitasnya. Kualitas sumber daya manusia berpadu dengan keterampilan, profesionalisme, sertakompetensi di bidangnya, sedangkan kuantitas berkaitan dengan jumlah sumber daya manusia apakah sudah cukup untuk melingkupi seluruh kegiatan yang direncanakan. Sumber daya manusia sangat mempengaruhi keberhasilan implementasi, sebab tanpa sumber daya manusia yang baik, implementasi kebijakan akan berjalan lambat

Hal ini sesuai dengan penelitian sebelumnya yang dilakukan oleh Elvianita (2012) tentang Pengaruh Sumber Daya Organisasi Terhadap Kesiapsiagaan Petugas Penanggulangan Bencana Menghadapi Bencana Banjir di Kabupaten Aceh Timur memperoleh hasil adanya pengaruh pada sumber daya di organisasi seperti personil terhadap kesiapsiagaan. Begitu juga menurut Dewi (2010) yang membuktikan bahwa kesiapsiagaan SDM kesehatan akan mengalami peningkatan 2,5 kali pada sumber daya manusia yang memperoleh pelatihan dibanding sumber daya manusia yang tidak mendapatkan pelatihan.

Dalam konteks kuantitas dukungan sumber daya manusia dapat disimpulkan cukup dalam memberikan pelayanan kesehatan pada penanggulangan bencana. Implementasi kebijakan akan lebih mudah diterapkan bila sumber daya manusia yang dibutuhkan ada, begitu juga dengan penanggulangan bencana bidang 
kesehatan. Implementasi pada tahap pra bencana, bencana dan pasca bencana dapat dijalankan secara bauik, meskipun ada beberapa capaian yang tidak dilakukan disebabkan karena kualitas sumber daya manusianya.

Beberapa hal dalam penanganan bencana bidang kesehatan yang dipengaruhi oleh kondisi sumber daya manusia, diantaranya, pada saat pra bencana beberapa aktivitas yang tidak tampak dalam penanggulangan bencana antara lain, pembuatan peta deomedik rawan bencana dan perencanaan kontingensi. Berdasarkan wawancara mendalam kedua hal ini tidak dilakukan disebabkan karena tim dinas kesehatan tidak memiliki kemampuan membuat peta deomedik sehingga dinas kesehatan beharap pada BPBD kabupaten kota untuk membuat peta tersebut.

Dalam konteks pra bencana kebutuhan akan kualitas sumber daya manusia dalam melakukan hal-hal yang mendukung aktivitas penanggulangan bencana tidak dimiliki oleh dinas kesehatan, sehingga harus berkordinasi dengan BPBD Aceh Utara. Menurut Sedarmayanti (2010) bahwa keterampilan memiliki andil yang cukup besar besar untuk meningkatkan produktivitas dalam menangani bencana di bidang kesehatan, oleh sebab perlu dilakukan upaya-upaya untuk meningkatkan keterampilan sumber daya manusia, guna mewujudkan penanganan bencana bidang kesehatan yang lebih berkualitas.

Pada saat bencana, implementasi kebijakan penanggulangan bencana bidang kesehatan secara keseluruhan dapat dilakukan. Sumber daya merupakan salah satu faktor yang membuat implementasi berjalan dengan baik. Aktivitas yang dilakukan saat bencana merupakan aktivitas pelayanan bidang kesehatan yang sehari-hari dilakukan oleh sumber daya manusia bidang kesehatan, sehingga hal tersebut memudahkan dalam implementasi kebijakan yang ada.
Pada saat pasca bencana hampir keseluruhan kegiatan dilakukan tim kesehatan dalam menanggulangi bencana di bidang kesehatan, hanya beberapa aktivitas yang belum sempurna dilakukan bila dibandingkan dengan Kepmenkes RI adalah penentuan strategi intervensi berdasarkan penilaian status gizi. Belum terlihat secara khusus intervensi di pengungsian berdasarkan pengukuran ulang gizi namun dilakukan inspeksi saja sehingga intervensi yang dilakukan hanya bersifat reaktif, artinya akan bereaksi bila ada kasusnya

Keberhasilan dalam proses pengimplementasian kebijakan bergantung pada kemampuan memanfaatkan sumberdaya yang sudah tersedia. Manusia merupakan sumber daya yang sangat penting didalam penentuan keberhasilan dari proses implementasi. Tetapi di luar sumberdaya manusia, sumberdaya-sumberdaya yang lainnya yang perlu perhitungan yaitu sumber daya financial serta sumber daya waktu. Ketiga sumber daya ini akan saling mendukung dalam implementasi suatu kebijakan.

Proses penting yang harus benarbenar dilakukan adalah perencanaan sumber daya manusia yang matang. Dinas kesehatan harus merencanakan untuk perekrutan sumber daya manusia yang dapat memenuhi kualitas dalam implementasi penanggulangan bencana. Alternatif lainnya adalah dengan meningkatkan kemampuan sumber daya manusia melalui pelatihan yang dapat dapat meningkatkan kemampuan teknis dalam penanggulangan bencana.

\section{Analisis Dukungan Sarana dan Prasarana dalam Implementasi Kebijakan Penanggulangan Bencana Bidang Kesehatan}

Sarana dan Prasarana adalah seluruh potensi fisik yang dialokasikan untuk mendukung implementasi kebijakan penanggulangan bencana bidang kesehatan di Kabupaten Aceh Utara. 
Selain manusia sarana dan prasarana merupakan substansi yang sangat diperlukan untuk mengimplementasikan sebuah kebijakan salah satunya adalah kebijakan penanggulangan bencana bidang kesehatan.

Hasil penelitian menunjukkan bahwa sarana dan prasarana tidak bisa terlepas dari implementasi kebijakan penanggulangan bencana bidang kesehatan. Artinya hampir semua proses dalam penanggulangan bencana bidang kesehatan memerlukan dukungan sarana dan prasarana. Dinas kesehatan yang secara spesifik bertanggung jawab dalam bidang kesehatan tergolong kurang memiliki sarana dan prasarana yang bersifat mendukung pelayanan kesehatan. Akan tetapi sarana dan prasarana banyak dibantu oleh dinas kesehatan, meskipun demikian tetap sarana dan prasarana mempengaruhi implementasi kebijakan penanggulangan bencana bidang kesehatan.

Hal ini sesuai dengan penelitian Aritonang (2014) yang memperoleh hasil bahwa kurangnya atau minimnya sarana dan prasarana yang memadai akan mempersulit fungsi dari koordinasi antar instansi yang sudah diatur oleh BPBD sebagai penanggungjawab kebencanaan, dimana kegiatan itu merupakan berbagai kegiatan dalam rangka menanggulangi bencana dibidang kesehatan. Begitu juga dengan penelitian Elvianita (2012) yang menemukan bahwa sarana adalah variabel yang paling berpengaruh terhadap kesiapsiagaan petugas penanggulangan bencana menghadapi bencana banjir di Kabupaten Aceh Timur.

Implementasi kebijakan penanggulangan bencana bidang kesehatan merupakan rangkaian kegiatan yang sangat membutuhkan manajemen yang baik, mulai dari tingkat pusat sampai di tingkat daerah. Menurut Nurjannah (2012) bahwa money, machine dan material yaitu unsur sarana serta prasarana yang sangat dibutuhkan agar kegiatan manajemen dan organisasi didalam penanganan bencana sehingga dapat berjalan dengan baik.

Bencana alam tentu memerlukan sarana secara khusus dalam mengatasi dampak dari bencana misalnya alat berat, peralatan medis, alat rescue dan lainnya. Tanpa adanya dukungan peralatan, upaya penanggulangan tentunya terhambat serta gagal. Sarana dan material merupakan unsur yang sangat penting dalam mendukung keberhasilan dari penanggulangan bencana. Banyak kejadian, terjadi dimana korban tidak tertolong karena tidak tersedia sarana dan materi yang memadai sehingga korban meningkat (Ramli, 2010).

Secara keseluruhan sarana dan prasarana memiliki peran yang sangat penting dalam implementasi kebijakan penanggulangan bencana bidang kesehatan. Sarana dan prasarana yang dimiliki dinas kesehatan tergolong kurang dalam mendukung penanggulangan bencana secara umum, akan tetapi secara khusus dalam bidang kesehatan, dinas kesehatan tidak mengalami kendala karena sarana dan prasarana yang ada di dinas kesehatan dan dimiliki oleh Puskesmas dapat dipergunakan untuk memberikan pelayanan kesehatan.

Sarana dan prasarana yang dimiliki oleh dinas dinilai sangat berperan dalam mendukung dinas kesehatan dalam mengimplementasikan kebijakan penanggulangan bencana bidang kesehatan. Alat yang cukup sampai pada tingkat Puskesmas sangat berperan dalam mendukung dinas kesehatan dalam memberikan pelayanan kesehatan. Sehingga secara garis kerja sarana yang dimiliki dinas kesehatan cukup berpengaruh dalam mendukung dinas menjalankan tugasnya dalam penanggulangan bencana.

Proses implementasi tersebut juga sangat didukung oleh ketersediaan peralatan dari BPBD kabupaten Aceh Utara, beberapa kebutuhan teknis mampu dibantu oleh BPBD sehingga dinas kesehatan dapat lebih meningkatkan 
pelayanan kesehatan dengan turun langsung ke daerah bencana.

Penyediaan alat-alat dalam mendukung pelayanan kesehatan sudah tersedia merata di tingkat Puskesmas,sehingga dinas kesehatan dapat dengan mudah mengimplementasikan kebijakan yang ada. Akan tetapi untuk jangka panjang penyediaan alat-alat non kesehatan juga diperlukan untuk meningkatkan jangkauan pelayanan kesehatan.

\section{KESIMPULAN}

Sumber daya manusia yang tersedia di Kabupaten Aceh Utara tergolong siap secara kuantitas dalam memberikan pelayanan kesehatan sebelum, saat atau setelah bencana, tetapi untuk dinas kesehatan masih kekurangan tenaga dengan kualifikasi mampu membuat peta rawan bencana dan rencana kontingensi. Sarana dan prasarana berupa peralatan yang dimiliki oleh dinas kesehatan sudah memadai dalam memberikan pelayanan kesehatan. Akan tetapi Dinas kesehatan masih sangat bergantung kepada BPBD dalam penyediaan alat pendukung seperti perahu karet, transpotasi yang dapat membantu langsung dinas kesehatan untuk terjun langsung ke daerah saat bencana.

Adapun saran dalam penelitian ini antara lain dinas kesehatan harus melakukan pelatihan kepada stafnya untuk meningkatkan pengetahuan dan ketrampilan dalam rangka penanggulangan bencana khususnya pembuatan peta geomedik pada daerah bencana dan stakeholder harus melakukan kesepakatan dan komitmen bersama dalam rangka penanggulangan bencana bidang kesehatan.

\section{DAFTAR PUSTAKA}

Aritonang, M. (2014) Implementasi Kebijakan Penanggulangan Bencana Bidang Kesehatan Pada
Erupsi Gunung Sinabung. Tesis, Universitas Sumatera Utara, Medan.

BNPB. (2011) Panduan Perencanaan Kontinjensi dalam Menghadai Bencana. Edisi ke dua. Badan Nasional Penanggulangan Bencana

Depkes RI. (2012) Pedoman Koordinasi Penanggulangan Bencana di Lapangan.

Departemen Kesehatan Republik Indonesia

Edward \& Widodo, Joko. (2011) Analisis Kebijakan Publik. Malang: Bayumedia

Elvianita., (2012) Pengaruh Sumber Daya Organisasi Terhadap

Kesiapsiagaan Petugas

Penanggulangan Bencana

Menghadapi Bencana Banjir di Kabupaten Aceh Timur, Medan: FKM USU

Kepmenkes RI Nomor 145 Tahun 2007 tentang Pedoman Penanggulangan Bencana di Bidang Kesehatan.

Nurjannah. (2012). Manajemen Bencana, Bandung: Alfabeta.

Peraturan Kepala Badan Nasional Penanggulangan Bencana (BNPB) No. 3 Tahun 2013 tentang Pedoman Pembentukan Badan Penanggulangan Bencana Daerah

Ramli, Soehatman. (2010) Manajemen Bencana. Jakarta: Dian Rakyat.

Kualitatif. Alfabeta. Bandung.

Sedarmayanti. (2010). Manajemen Sumber Daya Manusia dan Produktivitas Kerja. Bandung: Mondar Maju

Sugiyono. (2010). Metode Penelitian Kualitatif dan $R$ \& $D$; Penerbit CV Alfabeta, Bandung. 